\title{
Eczema atópico na criança e no adulto
}

\author{
Cristina Claro*
}

\section{RESUMO}

O eczema atópico é uma doença inflamatória da pele, crónica e recorrente, de incidência crescente. Muitas vezes de controlo difícil, requer a estreita colaboração entre as diversas especialidades com ela envolvidas.

Serão brevemente abordadas a epidemiologia e a etiopatogenia desta doença, e realçadas a clínica e a terapêutica, salientando-se aspectos práticos considerados importantes para o correcto acompanhamento dos doentes.

Palavras-chave: Eczema Atópico; Criança; Adulto.

\section{INTRODUÇÃO}

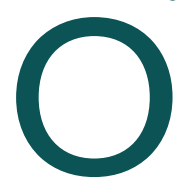

eczema atópico (EA) é uma entidade clínica individualizada que deve, no entanto, ser enquadrada num contexto global que é o de atopia. A atopia é uma condição geneticamente determinada que condiciona uma predisposição para o desenvolvimento de asma, rinite alérgica, eczema atópico e conjuntivite alérgica. É assim, frequente, no indivíduo com eczema atópico, uma história familiar de atopia, bem como o desenvolvimento, ao longo da sua vida, de outras patologias de base atópica.

\section{EPIDEMIOLOGIA/HISTÓRIA NATURAL}

O eczema atópico é uma doença, de distribuição universal, que afecta cerca de $20 \%$ das crianças e $5-10 \%$ dos adultos em todo o mundo. ${ }^{1} \mathrm{~A}$ sua incidência tem aumentado claramente desde os anos 40 do séc. XX, parecendo haver uma maior incidência em áreas urbanas de países industrializados. ${ }^{2}$ Pode ocorrer em qualquer faixa etária mas cerca de $90 \%$ dos casos manifesta-se antes dos 5 anos de idade. ${ }^{3}$

É uma doença crónica e recorrente, com períodos de remissão e de exacerbação, sendo estes muitas vezes sazonais. Há uma tendência global para a melhoria ao longo da infância, e cerca de metade dos casos terá de-

*Assistente Hospitalar Graduada de Dermatologia. Centro de Dermatologia Médico-cirúrgica de Lisboa saparecido por altura da puberdade. A previsão de um prognóstico individual quanto a uma eventual remissão é, no entanto, praticamente impossível, devendo esta informação ser transmitida de forma bem clara aos pacientes e/ou aos seus pais.

Uma percentagem importante dos doentes com eczema atópico desenvolverá rinite alérgica ou asma. ${ }^{4}$

\section{ETIOPATOGENIA}

O eczema atópico é, actualmente, reconhecido como uma doença de base genética, com expressão variável e influenciada por factores ambientais.

A base genética é sustentada por observações como a concordância para a presença de eczema ser de $0,8 \mathrm{em}$ gémeos monozigóticos e de 0,25 em gémeos dizigóti$\cos ^{5}$

Foram também identificadas, entre outras, várias mutações para o gene da filagrina em diversas populações com EA, sendo a filagrina uma proteína estrutural da pele, fundamental para a manutenção de uma função barreira normal. ${ }^{6}$ De facto, o modelo predominante para a explicação da patogenia do EA descreve uma barreira epidérmica anormal como defeito primário, decorrente de anomalias intrínsecas da pele, estruturais e funcionais. Uma deficiente função barreira condicionará uma maior perda de água transepidérmica e uma maior permeabilidade a agentes ambientais, alérgicos, irritativos e infecciosos, que vão interagir com o sistema imunológico. 


\section{CLÍNICA}

Na apresentação clínica do EA podemos observar lesões de eczema propriamente ditas, bem como outras manifestações associadas.

As lesões de eczema variam de distribuição e características de acordo com a idade e com a evolução da doença. Assim, na 1. infância (crianças com menos de 2 anos de idade) as lesões podem atingir qualquer local do tegumento, mas distribuem-se preferencialmente pela face (áreas convexas), couro cabeludo e superfícies de extensão dos membros, com predilecção pelos joelhos, punhos e mãos. A área da fralda está geralmente poupada. Nesta fase observam-se habitualmente lesões de eczema agudo, com eritema, pápulas e/ou vesículas, exsudação e crosta.

A partir dos 2 anos de idade as lesões tendem a envolver preferencialmente as superfícies de flexão dos membros (pregas antecubitais, escavados popliteus e punhos), a região cervical e os flancos. As lesões de eczema são habitualmente mais secas, menos exsudativas, sendo o eczema agudo gradualmente substituído por áreas de liquenificação, i.e., áreas de pele espessada em que o seu reticulado normal está muito acentuado, e que são a expressão clínica de um eczema crónico.

Nos adolescentes e adultos o quadro clínico é seme-

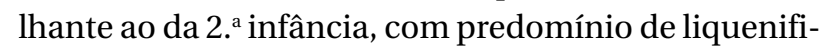
cação e atingimento preferencial das pregas flexoras. É também frequente o envolvimento das mãos, pés, pálpebras, genitais e, nas mulheres, dos mamilos.

Podem-se observar lesões de escoriação em todas as fases da doença, condicionadas pelo prurido, sintoma sempre presente e dominante no EA; que é, com frequência, suficientemente intenso para condicionar irritabilidade ou impedir o sono. A xerose cutânea é também uma alteração quase constante.

Nos atópicos existem ainda outras características físicas frequentes. São elas, entre outras, a ictiose, em que a pele toma o aspecto de escama de peixe; a queratose pilar, na qual se observa hiperqueratose folicular num fundo de eritema que atinge preferencialmente as regiões genianas e face externa dos braços e a prega de Dennie-Morgan, dupla prega muito característica na pálpebra inferior.

No decurso da história natural do EA podem surgir algumas complicações, sendo a mais frequente a sobre- infecção bacteriana das lesões de eczema, em geral por Staphylococcus aureus, agente que, com frequência, coloniza as lesões. ${ }^{7}$ Lesões de eczema estáveis que se tornam muito exsudativas e cobertas de crosta amarelada devem fazer suspeitar de infecção bacteriana secundária, impondo-se a instituição de antibioterapia sistémica.

\section{DIAGNÓSTICO}

O diagnóstico é essencialmente clínico. Baseia-se sobretudo na localização das lesões e características como o prurido, mas também na presença de outros dados que consolidarão o diagnóstico: a idade do doente, o carácter crónico e recorrente da doença, uma história pessoal ou familiar de atopia e a presença de características físicas mais frequentes nos atópicos.

A biópsia cutânea pode ser útil no diagnóstico diferencial com outras entidades, mas raramente é necessária.

Exames serológicos como a determinação do nível de IgE têm pouco interesse prático pois não afirmam ou excluem o diagnóstico e raramente modificam a abordagem terapêutica. As provas epicutâneas de contacto têm interesse quando existe suspeita clínica de uma dermite de contacto alérgica sobreposta ao eczema atópico (p. ex. agravamento do eczema com corticóide tópico fazendo suspeitar de alergia ao mesmo).

\section{TERAPÊUTICA}

O tratamento do eczema atópico inclui a terapêutica medicamentosa das crises e cuidados gerais que devem ser mantidos nos períodos intercrise. Nestes cuidados é fundamental manter a pele hidratada. Para isso os doentes devem tomar banhos rápidos e com água tépida, aplicando sempre um emoliente (emoliente significa que deixa a pele mais macia. Todos os hidratantes devem ser emolientes, logo, não sendo formalmente a mesma coisa, as duas designações são praticamente sinónimas) após o banho. Os banhos podem ser diários desde que sejam utilizados produtos lavantes com acção emoliente, adequados às peles atópicas. Os produtos utilizados podem ser em pain (sabonete sem agentes detergentes), óleo ou gel, de acordo com a preferência do indivíduo. O corpo deve ser seco com pequenas pancadas, sem esfregar, para não estimular o prurido e deve, em seguida, ser aplicado em todo o cor- 
po um emoliente, com o maior teor de óleo que o indivíduo tolerar. De salientar que existem linhas com teores crescentes de óleo (loção < creme < bálsamo), devendo-se recomendar, nas peles extremamente secas, as formulações mais compensadoras. Devem ser utilizados, de preferência, produtos para peles atópicas uma vez que a sua composição é particularmente adequada às características das mesmas; sabemos, no entanto, que estes produtos são quase sempre francamente caros pelo que, na impossibilidade de os comprar, podem ser utilizados, como alternativa, emolientes menos dispendiosos como a parafina líquida ou o óleo de amêndoas doces. Os emolientes podem ser reaplicados uma ou mais vezes ao dia, conforme necessário para combater a secura.

A eliminação de factores potencialmente agravantes do eczema é outra questão fundamental a considerar. Assim, os indivíduos com eczema atópico devem evitar o contacto com produtos lavantes com sabão, lã e fibras sintéticas; devem vestir apenas algodão em contacto directo com a pele. Devem também evitar a exposição ao calor excessivo e a ambientes secos, com baixo teor de humidade. O stress e a ansiedade podem agravar o eczema pelo que devem ser eficazmente combatidos.

O papel dos alergénios no EA é ainda controverso e insuficientemente esclarecido. A maioria dos dados parece indicar que a alergia tem um papel relevante apenas numa minoria de doentes, geralmente indivíduos com quadros clínicos graves. Crianças pequenas com EA estão mais frequentemente sensibilizadas a ali-

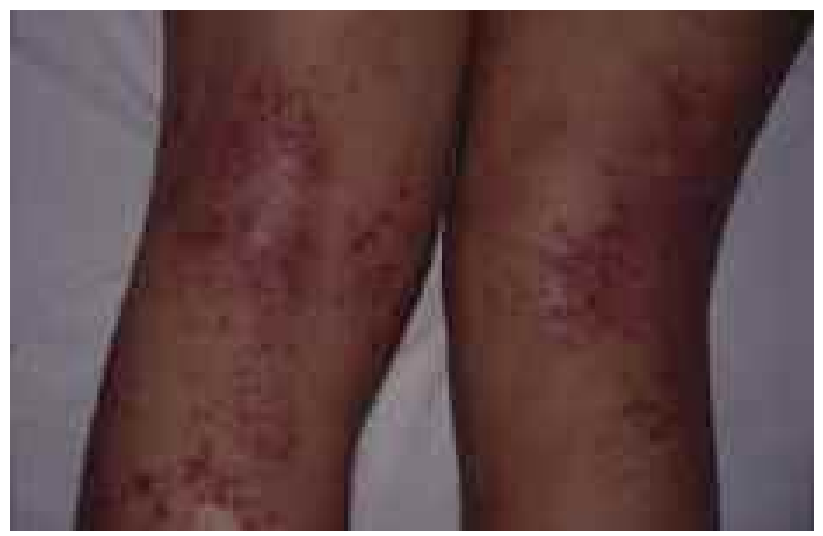

Figura 1. Lesões de eczema agudo nos escavados popliteus. mentos, ${ }^{8,9}$ enquanto que crianças com mais de 5 anos e adultos estão mais comummente sensibilizados a aeroalergénios. ${ }^{10}$ No entanto, sensibilização ao alergénio não é sinónimo de alergia clinicamente relevante. Assim, alimentos aos quais exista sensibilização só devem ser evitados se demonstradamente exacerbarem ou desencadearem o eczema. Dietas de eliminação sem identificação de agentes agravantes/desencadeantes têm que ser evitadas; para além de desnecessárias podem conduzir a deficits nutricionais e isolamento social.

O papel dos alergénios aerotransportados no EA, bem como estratégias terapêuticas apoiadas nesse papel estão insuficientemente estudados e necessitam clarificação. ${ }^{11}$

Na terapêutica das crises podem-se considerar e, quando necessário, associar as terapêuticas tópica e sistémica.

A terapêutica tópica consiste na utilização de agentes locais para combater a inflamação, sendo utilizados essencialmente dois grandes grupos: os corticóides e os inibidores da calcineurina.

Os corticóides tópicos são o standard of care do eczema atópico. ${ }^{11}$ Os corticóides devem ser aplicados uma vez por dia, na forma de creme nas lesões agudas, exsudativas, e em pomada nas lesões liquenificadas, até franca melhoria ou resolução das lesões. Um corticóide pouco potente (p. ex. hidrocortisona a 1 ou 2,5\%) é geralmente eficaz em doentes com EA moderado; um

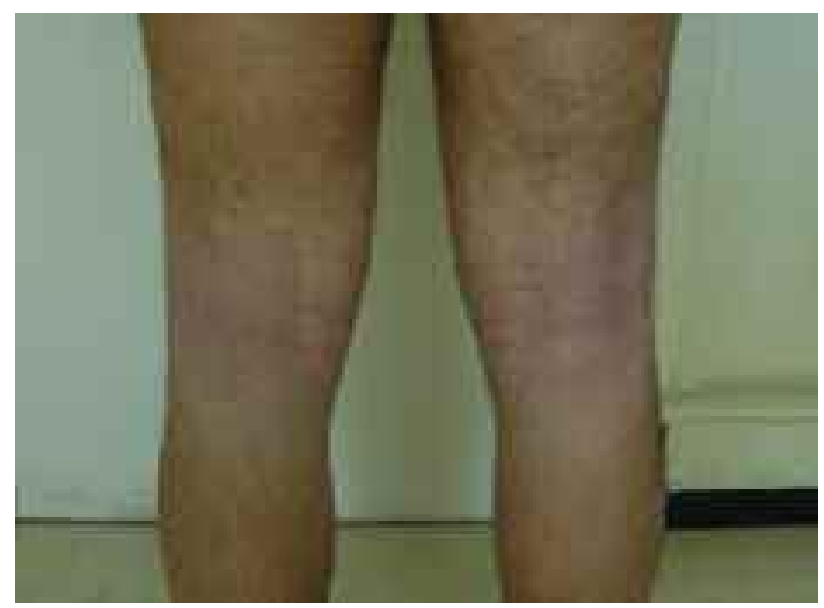

Figura 2. Eczema crónico com liquenificação. 
corticóide de média potência (p. ex. furuoato de mometasona, aceponato de metilprednisolona) pode ser necessário para eczemas mais graves.

Efeitos secundários locais como atrofia, estrias e telangiectasias limitam a utilização a longo prazo de corticóides potentes, principalmente na face e pregas. Deve-se assim utilizar o corticóide menos potente que se julgue eficaz para o caso em questão, e apenas durante o tempo indispensável, mas garantindo o controlo das lesões.

Os inibidores da calcineurina, pimecrolimus e tacrolimus, são eficazes no tratamento do EA em crianças e adultos. ${ }^{12}$ Ao contrário dos corticóides tópicos, não causam atrofia cutânea, pelo que são particularmente úteis na face, pescoço e pregas. Ambas as preparações tópicas estão aprovadas para o uso em doentes com mais de 2 anos de idade com EA não controlado com corticóides tópicos. O pimecrolimus existe formulado em creme e o tacrolimus em pomada, com as concentrações $0,03 \%$ e $0,1 \%$, sendo esta última indicada apenas para adultos. Estes agentes devem ser aplicados duas vezes por dia, sendo frequentes o ardor/sensação de picada nas primeiras aplicações. O pimecrolimus tende a ser mais bem tolerado que o tacrolimus, mas também a ser menos eficaz. A experiência acumulada a nível mundial com o uso destes medicamentos parece confirmar a segurança na sua utilização a longo prazo, apesar de relatos de uma possível relação entre o uso de inibidores da calcineurina e certos cancros (linfomas e cancro cutâneo). ${ }^{13}$

A terapêutica sistémica consiste principalmente na utilização de anti-histamínicos para controlo do prurido. Os anti-histamínicos sedativos (hidroxizina, dimentideno) são os mais adequados, pois este efeito é importante para o eficaz controlo do prurido e para permitir um sono sem interrupções. ${ }^{11}$

Os corticóides sistémicos podem ser utilizados em cursos curtos para controlo de episódios agudos, exuberantes, do eczema. Devem ser evitados no controle da doença crónica, pelos seus efeitos secundários, e por provocarem rebounds potencialmente graves do eczema quando interrompidos.

As sobreinfecções bacterianas, quase sempre a Staphylococcus aureus, devem ser tratadas com antibioterapia sistémica, sendo os antibióticos de eleição as cefalosporinas de $1 .{ }^{\mathrm{a}}$ geração ou as penicilinas resisten- tes às penicilinases.

Não há evidência que óleo de peixe, óleo de borragem ou outros, bem como suplementos vitamínicos ou minerais tenham qualquer eficácia terapêutica no EA. ${ }^{11}$

Finalmente, outras modalidades terapêuticas de utilização exclusiva nos eczemas graves são a fototerapia, a ciclosporina ou outros imunossupressores, modalidades estas claramente a serem orientadas por dermatologistas. De facto, é importante a referenciação adequada e atempada, sendo recomendada a referenciação nas seguintes circunstâncias:

- quando o diagnóstico é incerto

- na ausência de resposta à terapêutica adequada

- aquando da necessidade de utilização prolongada de corticóides potentes, para instituição de terapêutica alternativa

\section{REFERÊNCIAS BIBLIOGRÁFICAS}

1. Williams H, Robertson C, Stewart A, Aït-Khaled N, Anabwani G, Anderson $\mathrm{R}$, et al. Worldwide variations in the prevalence of symptoms of atopic eczema in the International Study of Asthma and Allergies in Childhood. J Allergy Clin Immunol 1999 Jan; 103 (1 Pt 1): 125-38.

2. Trepka MJ, Heinrich J, Wichmann HE. The epidemiology of atopic diseases in Germany: an east-west comparison. Rev Environ Health 1996 Jul-Sep; 11 (3): 119-31.

3. Kang K, Polster AM, Nedorost ST, et al. Atopic dermatitis. In: Bolognia JL, Jorizzo JL, Rapini RP, et al., editors. Dermatology. New York: Mosby; 2003. p. 199.

4. Eichenfield LF, Hanifin JM, Beck LA, Lemanske RF Jr, Sampson HA, Weiss ST, et al. Atopic dermatitis and asthma: parallels in the evolution of treatment. Pediatrics 2003 Mar; 111 (3): 608-16.

5. Schultz Larsen F. Atopic dermatitis: a genetic-epidemiologic study in a population-based twin sample. J Am Acad Dermatol 1993 May; 28 (5 Pt 1): 719-23.

6. Sandilands A, Smith FJ, Irvine AD, McLean WH. Fillagrin's fuller figure: a glimpse into the genetic architecture of atopic dermatitis. J Invest Dermatol 2007 Jun; 127 (6): 1282-4.

7. Huang JT, Abrams M, Tlougan B, Rademaker A, Paller AS. Treatment of Staphylococcus aureus colonization in atopic dermatitis decreases disease severity. Pediatrics 2009 May; 123 (5): e808-14.

8. Eller E, Kjaer HF, Høst A, Andersen KE, Bindslev-Jensen C. Food alergy and food sensitization in early childhood: results from the DARC cohort. Allergy 2009 Jul; 64 (7): 1023-9.

9. Hon KL, Leung TF, Ching G, Chow CM, Luk V, Ko WS, et al. Patterns of food and aeroallergen sensitization in childhood eczema. Acta Paediatr 2008 Dec; 97 (12): 1734-7.

10. Pónayi G, Hidvégi B, Németh I, Sas A, Tamesvári E, Kárpáti S. Contact and aeroallergens in adulthood atopic dermatitis. J Eur Acad Dermatol Venereol 2008 Nov; 22 (11): 1346-55.

11. Hanifin JM, Cooper KD, Ho VC, Kang S, Kreftchik BR, Margolis DJ, et al. Guidelines of care for atopic dermatitis, developed in accordance with the 
American Academy of Dermatology (AAD)/American Academy of Dermatology Association "Administrative Regulations for Evidence-Based Clinical Practice Guidelines". J Am Acad Dermatol 2004 Mar; 50 (3): 391-404.

12. Ashcroft DM, Dimmock P, Garside R, Stein K, Williams HC. Efficacy and tolerability of topical pimecrolimus and tacrolimus in the treatment of atopic dermatitis: meta-analysis of randomised controlled trials. BMJ 2005 Mar 5; 330 (7490): 516.

13. Berger TG, Duvic M, Van Voorhees AS, VanBeek MJ, Frieden IJ; American Academy of Dermatology Association Task Force. The use of topical calcineurin inhibitors in dermatology: safety concerns. Report of the American Academy of Dermatology Task Force. J Am Acad Dermatol 2006 May; 54 (5): 818-23.

\section{CONFLITOS DE INTERESSE}

Declaro para os devidos efeitos não haver qualquer conflito de interesses para a realização deste trabalho, bem como não ter havido qualquer financiamento para a realização do mesmo.

\section{ENDEREÇO PARA CORRESPONDÊNCIA}

Cristina Claro

Av. Guerra Junqueiro, 13-2. ${ }^{\circ}$ esq. 1000-166 Lisboa

cristina.claro@netcabo.pt

Recebido em 05/12/2010

Aceite para publicação em 15/02/2011

\section{ABSTRACT}

\section{ATOPIC DERMATITIS IN CHILDREN AND ADULTS}

Atopic dermatitis is a chronic relapsing inflammatory skin condition, of increasing incidence. Strict collaboration between the specialities that deal with this illness is essential.

The epidemiology, aetiology and pathogenesis of atopic dermatitis will be briefly approached; the clinical features of the disease and some practical aspects of its treatment will be addressed.

Keywords: Atopic Dermatitis; Children; Adults. 